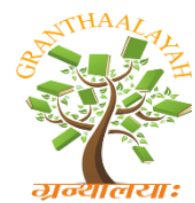

INTERNATIONAL JOURNAL OF RESEARCH GRANTHAALAYAH A knowledge Repository

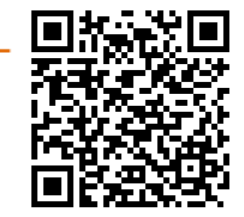

Social

\title{
EFFECT OF CONTINUOUS RUNNING ON ENDURANCE OF MEN KABADDI PLAYERS
}

\author{
Dr. A. Subradeepan *1 \\ ${ }^{* 1}$ Assistant Professor, Department of Physical Education \& Sports Sciences, Annamalai \\ University, Tamilnadu, India
}

DOI: https://doi.org/10.29121/granthaalayah.v5.i5(SE).2017.1959

\begin{abstract}
The purpose of the study was to investigation the effect of continuous running on endurance of men kabaddi players. To achieve the purpose of this study, thirty men kabaddi players selected from the Department of Physical Education and Sports Sciences, Annamalai University, Tamilnadu, India. The age, height and weight of the subjects ranged from 19 to 21 years, 155 to 169 centimetres and 58 to 68 kilograms respectively. They were divided into two groups; each group consisted of fifteen subjects. Group-I underwent continuous running and group-II acted as control who does not participate in any training programme. The data collected from the two groups prior to and post experimentation were statistically analyzed by analysis of covariance (ANCOVA). The experimental group had significant improvement on endurance when comparing to the control group.

Keywords: Continuous Running and Endurance.

Cite This Article: Dr. A. Subradeepan. (2017). "EFFECT OF CONTINUOUS RUNNING ON ENDURANCE OF MEN KABADDI PLAYERS." International Journal of Research - Granthaalayah, 5(5)SE, 7-10. https://doi.org/10.29121/granthaalayah.v5.i5(SE).2017.1959.
\end{abstract}

\section{Introduction}

Endurance is a term widely used in sport and can mean many different things to many different people. In sports it refers to an athlete's ability to sustain prolonged exercise for minutes, hours, or even days. Endurance requires the circulatory and respiratory systems to supply energy to the working muscles in order to support sustained physical activity. When most people talk about endurance they are referring to aerobic endurance, which is often equated with cardiovascular fitness. The objective of endurance training is to develop the energy production systems to meet the demands of activity for as long as they are required.

Endurance training is the deliberate act of exercising to increase stamina and endurance. Exercises for endurance tend to be aerobic in nature versus anaerobic movements. Aerobic 
exercise develops slow twitch muscles. Performing these exercises strengthens and elongates the muscles for preparation of extended periods of use. Frequent and regular physical exercise boosts the immune system, and helps prevent the "diseases of affluence" such as heart disease, cardiovascular disease, Type 2 diabetes and obesity (Stampfer, et. al., 2000). It also improves mental health, helps prevent depression, helps to promote or maintain positive self-esteem, and can even augment an individual's sex appeal or body image, which again is also linked with higher levels of self-esteem. Childhood obesity is a growing global concern and physical exercise may help decrease the effects of childhood obesity in developed countries (Connor and others, 2005).

Kabaddi is a contact team sport that originated in Indian subcontinent in Tamil Nadu. It is popular in South Asia and is the state game of the Indian states of TamilNadu, Maharashtra, Bihar, Andhra Pradesh, Telangana and Punjab. It is also the national sport of Bangladesh. Two teams compete, each occupying its own half of the court. They take turns sending a "raider" into the opposing team's half and earn points if the raider manages to touch opposing team members and return to the home half, all while taking only a single breath. If however the raider is tackled and prevented from returning, the opposing team earns the point.

\section{Methodology}

The purpose of the study was to investigation the effect of continuous running on endurance of men kabaddi players. To achieve the purpose of this study, thirty men kabaddi players selected from the Department of Physical Education and Sports Sciences, Annamalai University, Tamilnadu, India. The age, height and weight of the subjects ranged from 19 to 21 years, 155 to 169 centimetres and 58 to 68 kilograms respectively. They were divided into two groups; each group consisted of fifteen subjects. Group-I underwent continuous running and group-II acted as control who does not participate in any training programme. The experimental group subjects were participated in continuous running three days per week for eight weeks, duration of the training programme on 40 minutes (including warm up and warm down) per day. Once in two weeks the training load was increased 5\% of their HRR. Endurance was measured by 12 min run/walk test. The data collected from the two groups prior to and post experimentation were statistically analyzed by analysis of covariance (ANCOVA).

\section{Results}

Table 1: ANALYSIS OF COVARIANCE ON ENDURANCE OF CONTINUOUS RUNNING AND CONTROL GROUPS

\begin{tabular}{|l|l|l|l|l|l|l|l|}
\hline & $\begin{array}{l}\text { Experimental } \\
\text { Group }\end{array}$ & $\begin{array}{l}\text { Control } \\
\text { Group }\end{array}$ & SoV & $\begin{array}{l}\text { Sum of } \\
\text { Squares }\end{array}$ & df & $\begin{array}{l}\text { Mean } \\
\text { squares }\end{array}$ & $\begin{array}{l}\text { 'F' } \\
\text { ratio }\end{array}$ \\
\hline $\begin{array}{l}\text { Pre-test } \\
\text { Mean } \\
\text { SD }\end{array}$ & 1176.66 & 1168.67 & B & 580.00 & 1 & 580.00 & \multirow{2}{*}{0.21} \\
\cline { 1 - 7 } & 74.77 & 47.39 & W & 78506.66 & 28 & 2803.80 & \\
\hline Post-test & 1824.66 & 1170.66 & B & 3208870.00 & 1 & 3208870.00 & $733.05^{*}$ \\
\hline
\end{tabular}




\begin{tabular}{|l|l|l|l|l|l|l|l|}
$\begin{array}{l}\text { Mean } \\
\text { SD }\end{array}$ & 94.41 & 50.26 & $\mathrm{~W}$ & 122566.66 & 28 & 4377.38 & \\
\hline $\begin{array}{l}\text { Adjusted } \\
\begin{array}{l}\text { Post-test } \\
\text { Mean }\end{array}\end{array}$ & 1822.93 & 1172.40 & $\mathrm{~B}$ & 3155601.49 & 1 & 3155601.49 & \multirow{2}{*}{$789.99 *$} \\
\cline { 4 - 8 } & & & $\mathrm{W}$ & 107850.47 & 27 & 3994.46 & \\
\hline
\end{tabular}

(The required table value for significance at 0.05 level of confidence with degrees of freedom $1 \& 28$ and $1 \& 27$ are 4.20 and 4.21 respectively)

*Significant at .05 level of confidence

Table-1 shows that the adjusted post test means on endurance of continuous running and control groups are 1722.93 and 1072.40 respectively. The obtained 'F' ratio value of 790.47 for adjusted post test means on endurance of continuous running and control groups were higher than the required table value of 4.21 for the degrees of freedom 1 and 27 at 0.05 level of confidence. It is observed from this finding that significant differences exist among the adjusted post test means of experimental and control groups on endurance. Due to the endurance of continuous running the endurance of the subject's is significantly improved.

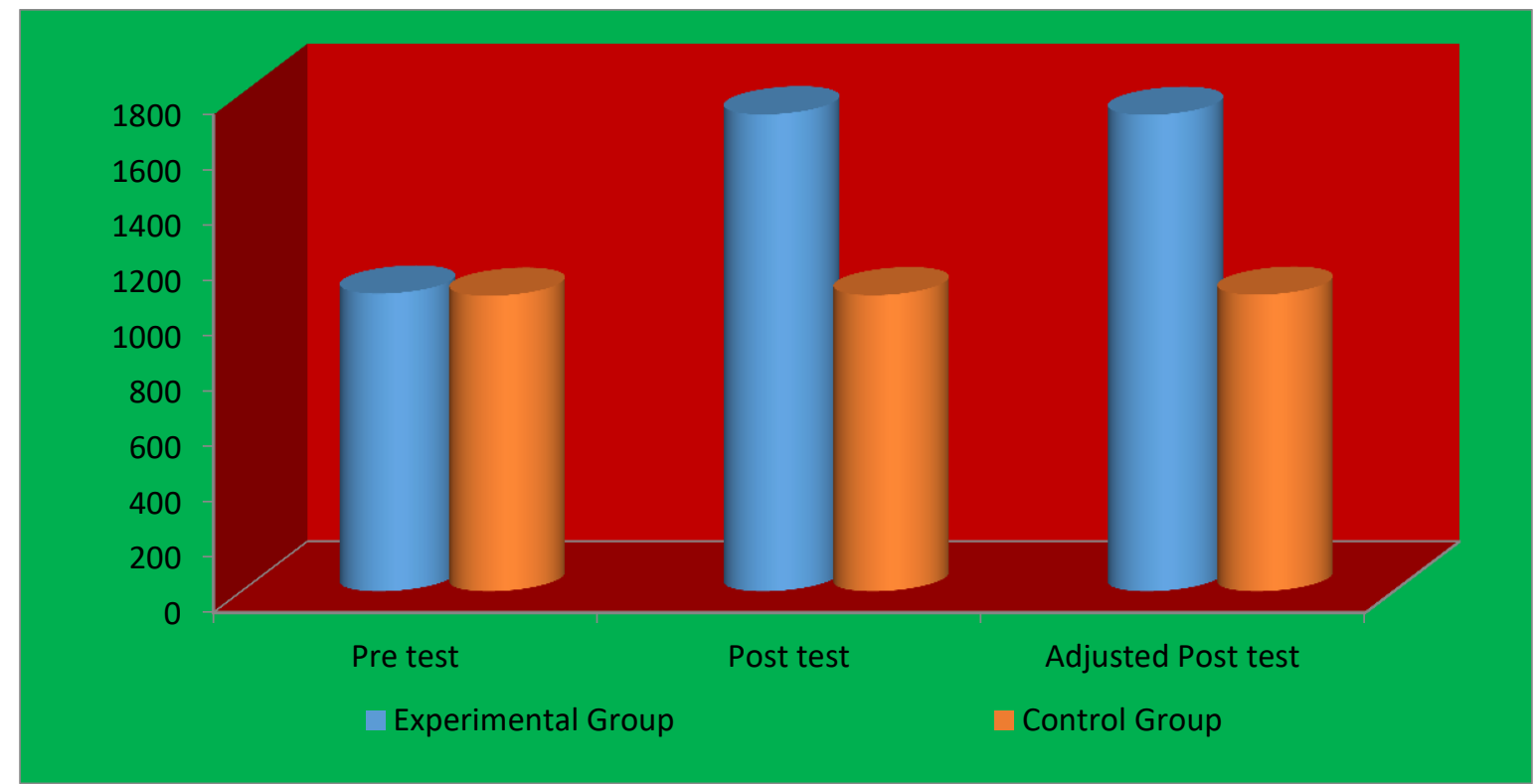

Figure 1: CYLINDER DIAGRAM ON ENDURANCE OF ENDURANCE OF CONTINUOUS RUNNING AND CONTROL GROUPS

\section{Discussion and Findings}

The results of the study showed that there was a significant improvement on endurance of continuous running group when compared to the control group. The following studies are supporting with my study results. Xiaochen and other (2015) examined the effects of exercise training on cardiorespiratory fitness and biomarkers of cardiometabolic health. The result of the study showed that the physical exercise significantly improved on cardiorespiratory fitness. Benser and others (2015) examined the association of physical activity (PA), cardiovascular fitness (CVF) and fatness with total homocysteine (tHcy) concentrations in European adolescents; they found that physical activity increased the cardiovascular fitness. 


\section{References}

[1] Benser, J., Valtuena, J., Ruiz, J.R., Mielgo-Ayuso, J., Breidenassel, C., Vicente-Rodriguez, G., Ferrari, M., Widhalm, K., Manios, Y., Sjostrom, M.,Molnar, D., Gomez-Martínez, S., Kafatos, A., Palacios, G., Moreno, L.A., Castillo, M.J., Stehle, P., Gonzalez-Gross, M., (2015). Impact of physical activity and cardiovascular fitness on total homocysteine concentrations in european adolescents. J Nutr Sci Vitaminol. 61(1): p. 45-54.

[2] Connor, D., Crowe, M., Spinks, W., (2005). Effects of static stretching on leg capacity during cycling. Turin, 46(1), 52-56.

[3] Golden, S. A. R. (2011). Strategy For Success Of Human Beings:-Time Management.

[4] Golden, S. A. R. (2017). Recent Research In Social Science \& Humanities.

[5] Stampfer, M. J., Hu, F. B., Manson, J. E., Rimm, E. B., Willett, W. C., (2000). "Primary prevention of coronary heart disease in women through diet and lifestyle". New England Journal of Medicine. 343 (1): 16.

[6] Xiaochen Lin., Xi Zhang., Jianjun Guo., Christian K. Roberts., Steve McKenzie., Wen-Chih Wu., Simin Liu., Yiqing Song., (2015). Effects of exercise training on cardiorespiratory fitness and biomarkers of cardiometabolic health: a systematic review and meta-analysis of randomized controlled trials. J Am Heart Assoc. 2015: 4. 